\title{
Research on the Rotor Flux Model of Induction Motor based on MATLAB
}

\author{
Genghuang Yang, Xiayi Hao \\ School of Automation and Electrical Engineering \\ Tianjin University of Technology and Education \\ Tianjin, China \\ yenghuang@126.com
}

\author{
Xin $\mathrm{Su}$, Xiaotian Xu \\ Chengxi Power Supply Branch \\ Tianjin Electrical Power Company \\ Tianjin, China \\ tutezdh1203@163.com
}

\begin{abstract}
Based on the Vector Control theory, this paper uses the MATLAB/SIMULINK simulation software to build and simulate the rotor flux model in the induction motor. The result is obtained that the two waveforms produced by simulating the rotor flux current model and voltage model are credible under the ideal conditions through comparing the two simulation waveforms. After the waveforms are compared with the other simulated by original induction motor model, it finds that the change of motor parameters has a great influence on the rotor flux current model and that the integral part of the motor model affects the rotor flux voltage model. Thus, the following conclusion can be learned that the current model is suitable for low speed operation of the motor and the voltage model for high speed operation.
\end{abstract}

Keywords-rotor flux linkage model; MATLAB/SIMULINK simulation; the induction motor speed adaptability; the Vector Control theory

\section{INTRODUCTION}

The Vector Control, which is also called Flux Orientation Control (FOC), rules the direction of the flux vector that is rotated at the synchronous speed as the reference axis direction and builds the mathematical model of the motor. Experiments show that the speed control performance of induction motor utilized Vector Control can be comparable with that of DC motor. Therefore, Vector Control has the high performance of static-dynamic speed control of induction motor [1-3].

In this paper, the mathematical model of rotor flux linkage, which is based on the Vector Control theory and the dynamic speed control model of three-phase induction motor, is designed and built by MATLAB/SIMULINK simulation software. It can make some reasonable assumptions with a further study of the model. To verify the hypotheses, the model is transformed and re-simulated. By comparing the differences between the former and latter, it can get some results and do evaluation for the built flux linkage model.

\section{BUILDING THE MATHEMATICAL MODEL OF ROTOR FLUX LINKAGE OF INDUCTION MOTOR}

In order to realize the purpose of controlling the rotational speed of the motor, it is necessary to build the corresponding relationship between the induction motor and the DC motor.

This paper is supported by the project of Tianjin University of Technology and Education (XJKC030155 and XJKC031112).
There are some theories about transformation of coordinates, for example, Clarke Transformation and Park Transformation [4]. In the theoretical field, the coordinate system transformations can realize the conversion of the induction motor to the DC motor, and in reality, these methods can provide the foundational knowledge for the Vector Control.

To create ideal study environment, the model needs to be simplified:

1) The parameters of three-phase windings are identical and the synthetic magnetomotive force presents the characteristic as sine wave after the motor is powered;

2) Neglect the saturation of magnetic circuit and effects of input noise frequency;

3) Neglect the core loss;

4) Neglect the effect of temperature rise on the resistance due to the skin effect of windings.

The simplified mathematical model of the induction motor includes the flux linkage equation, the voltage equation, the motion equation and the torque equation. By combining the above equations, the rotor flux linkage model of the induction motor can be obtained. Among the rotor flux linkage model, if the independent variable is current, then it calls the rotor flux current model, and if is voltage, it calls the rotor flux voltage model.

\section{A. The Rotor Flux Current Model}

The rotor flux current model of induction motor is given by

$$
\left\{\begin{array}{l}
\psi_{r \alpha}=\frac{1}{T_{r} p+1}\left(L_{m} i_{s \alpha}-\omega T_{r} \psi_{r \beta}\right) \\
\psi_{r \beta}=\frac{1}{T_{r} p+1}\left(L_{m} i_{s \beta}-\omega T_{r} \psi_{r \alpha}\right)
\end{array} .\right.
$$

Where $\psi_{r \alpha}, \psi_{r \beta}$ are the component on the $\alpha, \beta$ axes respectively in two-phase stationary coordinate system, and $\omega$ is mechanical angular velocity, and $L_{m}$ is the mutual inductance between stator and rotor which are coaxial and equivalent each other, and $i_{s \alpha} 、 i_{s \beta}$ are current of stator 
windings in tow-phase stationary coordinate system, and $\mathrm{p}$ is the differential operator, and $T_{r}=L_{m} / R_{r}$, where $R_{r}$ is the resistance value of rotor windings.

Based on the two-phase rotating coordinate system of the rotor flux-oriented, the other rotor flux current model is obtained by [5]

$$
\begin{gathered}
T_{e}=\frac{n_{p} L_{m}}{L_{r}} i_{s t} \psi_{r}, \\
\omega_{s}=\frac{R_{r} i_{s t}}{\psi_{r}}=\frac{L_{m} i_{s t}}{T_{r} \psi_{r}}, \\
\psi_{r}=\frac{L_{m}}{T_{r} p+1} i_{s m} .
\end{gathered}
$$

Where $T_{e}$ is electromagnetic torque, and $n_{p}$ is pole pairs of induction motor, and $L_{r}$ is the self-inductance of rotor which is equivalent in two-phase stationary coordinate system, and $\psi_{r}$ is the rotor flux linkage in two-phase rotating coordinate system, and $i_{s t} 、 i_{s m}$ are rotor flux-oriented current in twophase stationary coordinate system.

\section{B. The Rotor Flux Voltage Model}

The rotor flux voltage model is given by (5).

$$
\left\{\begin{array}{l}
\psi_{r \alpha}=\frac{L_{r}}{L_{m}}\left[\int\left(u_{s \alpha}-R_{s} i_{s \alpha}\right) d t-\sigma L_{s} i_{s \alpha}\right] \\
\psi_{r \beta}=\frac{L_{r}}{L_{m}}\left[\int\left(u_{s \beta}-R_{s} i_{s \beta}\right) d t-\sigma L_{s} i_{s \beta}\right]
\end{array}\right.
$$

Where $u_{s \alpha} 、 u_{s \beta}$ are voltages of state windings in two-phase stationary coordinate system, and $R_{s}$ is the resistance value of stator windings, and $i_{s \alpha} 、 i_{s \beta}$ are currents of stator windings in two-phase stationary coordinate system, and $L_{s}$ is the selfinductance of stator windings which is equivalent in two-phase stationary coordinate system, and $\sigma=1-L_{m}{ }^{2} /\left(L_{s} L_{r}\right)$.

\section{MODEL CONSTRUCTION AND SIMULATION}

\section{A. Constructing the Rotor Flux Current Model}

Since the value of flux linkage of the first rotor flux current model is likely to diverge when the model is calculated, this paper adopts the second rotor flux current model for study, which is also called the current model of rotor flux-oriented.

The rotor flux current model can be built by (2), (3) and (4). The structure of model is shown in Fig.1.

\section{B. Constructing the Rotor Flux Voltage Model}

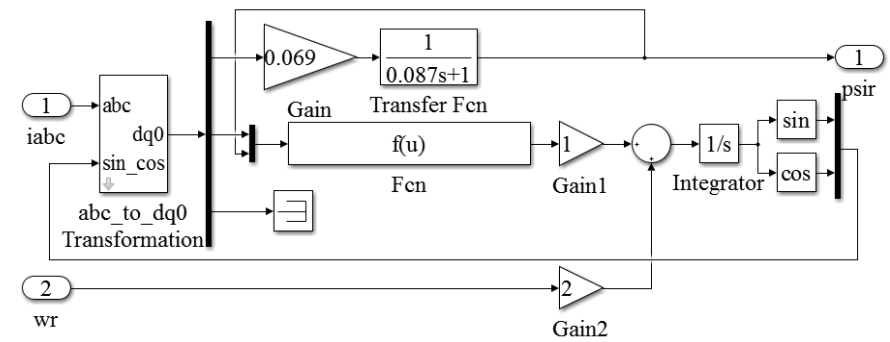

Fig. 1. The rotor flux current model

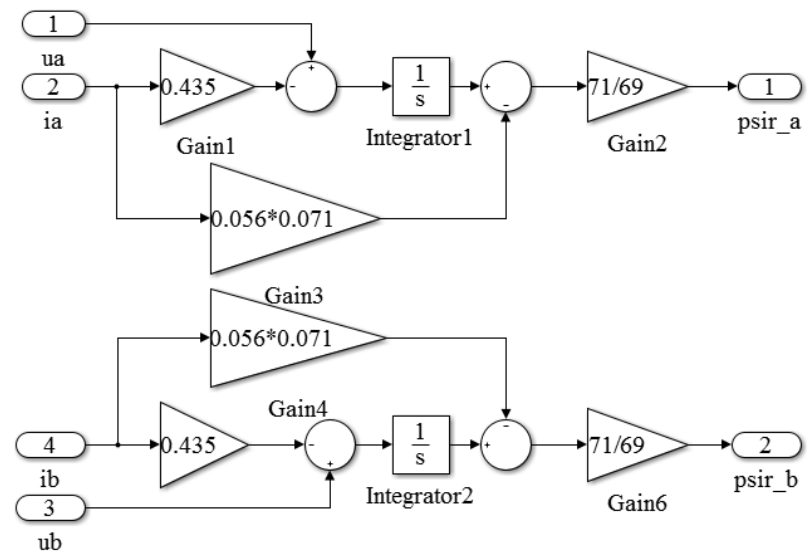

Fig. 2. The rotor flux voltage model

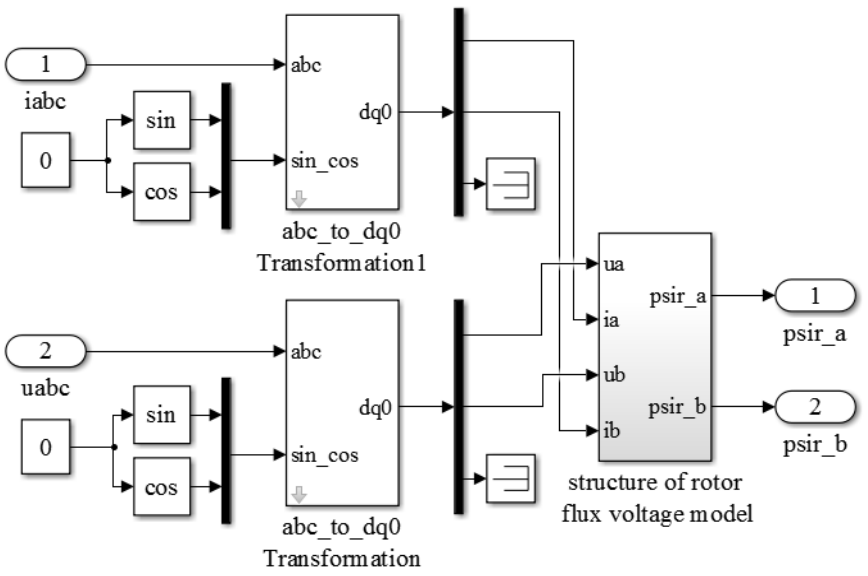

Fig. 3. The external structure of rotor flux voltage model

An extern structure of the rotor flux voltage model is needed because of the inputs. It is shown as Fig.3.

\section{Structuring the Simulation Model of Rotor Flux Linkage of Induction Motor}

The parameters of the rotor flux model are shown in the Table I. Fig.4 shows the whole simulation model of the rotor flux linkage of induction motor. 
TABLE I. THE PARAMETERS OF INDUCTION MOTOR

\begin{tabular}{c|c|c|c}
\hline Rated Voltage $/ U$ & $380 \mathrm{~V}$ & DC Power $/ U$ & $510 \mathrm{~V}$ \\
\hline Rated Frequency $/ f$ & $50 \mathrm{~Hz}$ & Stator Self-inductance $/ L_{s}$ & $0.071 \mathrm{H}$ \\
\hline Stator Resistance $/ R_{s}$ & $0.435 \Omega$ & Rotor Self -inductance $/ L_{r}$ & $0.071 \mathrm{H}$ \\
\hline Stator mutual Inductance $/ L_{l s}$ & $0.002 \mathrm{H}$ & Leakage Coefficient $/ \sigma$ & 0.056 \\
\hline Rotor Resistance $/ R_{r}$ & $0.816 \Omega$ & Time Constant $/ T_{r}$ & $0.087 \mathrm{~s}$ \\
\hline Rotor mutual Inductance $/ L_{l r}$ & $0.002 \mathrm{H}$ & Moment of Inertia $/ J$ & $0.19 \mathrm{~kg} \cdot \mathrm{m}^{2}$ \\
\hline Inter-group Interaction $/ L_{m}$ & $0.069 \mathrm{H}$ & & \\
\hline
\end{tabular}

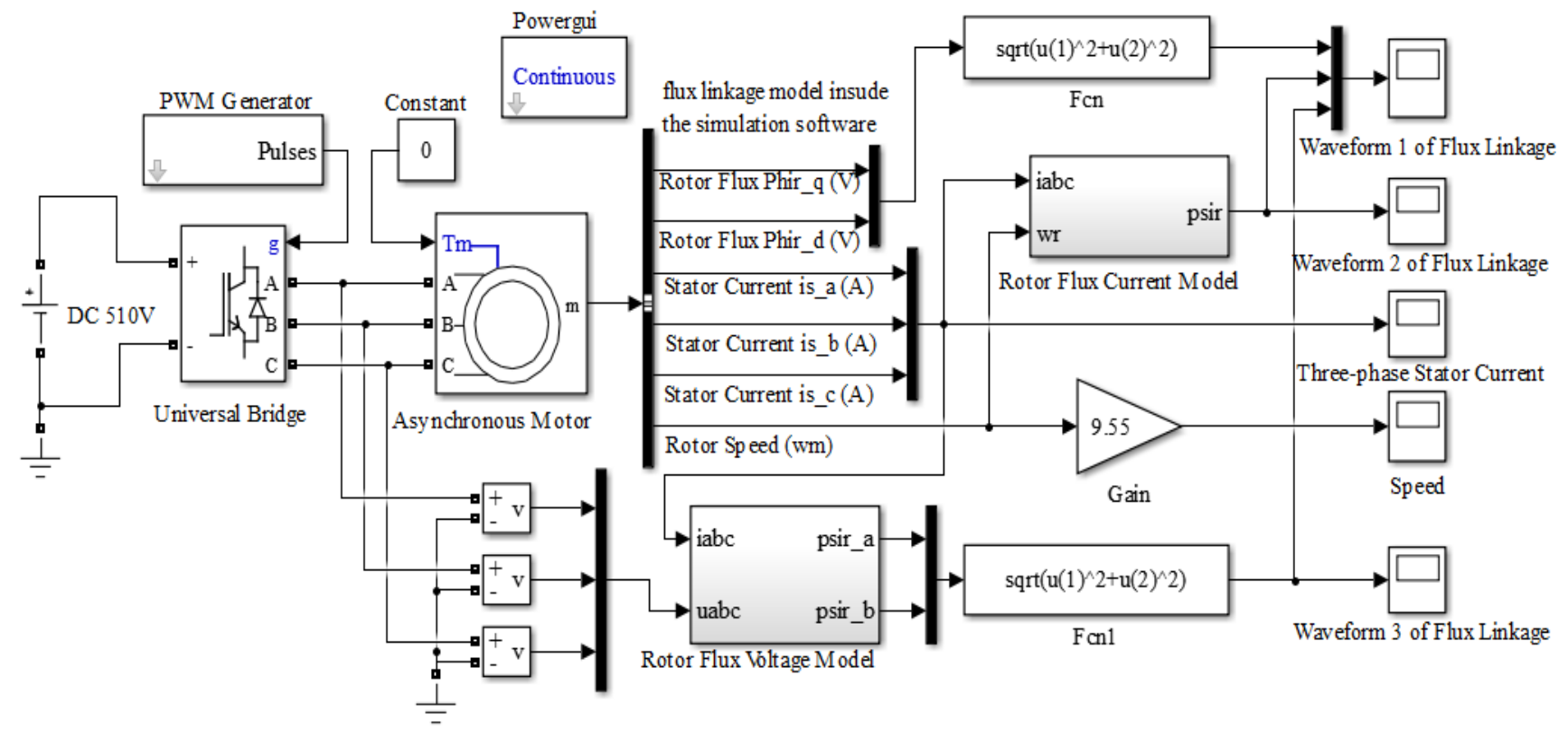

Fig. 4. The simulation model of rotor flux linkage

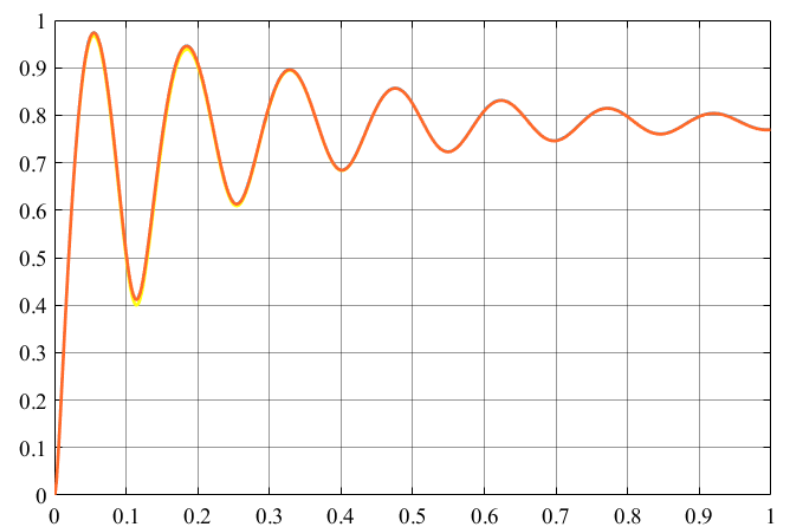

(a)

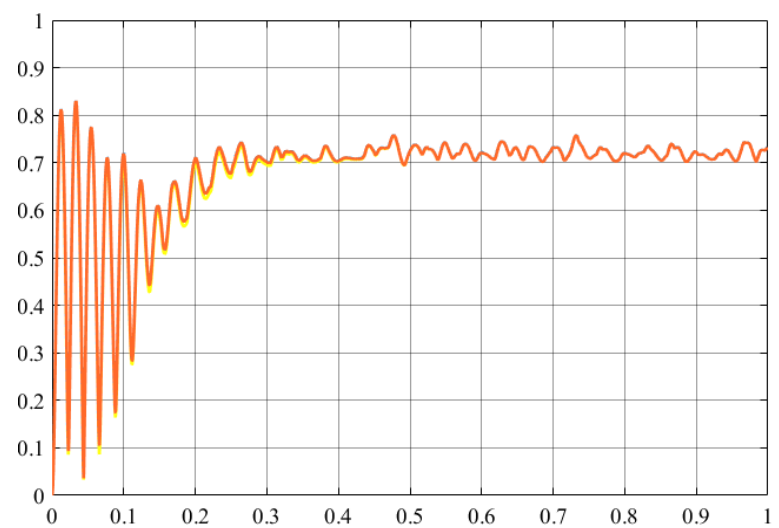

(b)

Fig. 5. (a) Frequency is $10 \mathrm{~Hz}$ and modulation degree is 0.2 . (b) Frequency is $50 \mathrm{~Hz}$ and modulation degree is 0.9 .

The data are used as the operating parameters of the simulation model [6]. The simulation waveforms are shown in Fig.5.

\section{RESEARCH ON Two FluX LinKAGE MODELS}

In order to research the two flux linkage models, they are compared with the flux linkage model inside the simulation software. By observing the coincidence degree of simulation 
waveforms produced by the three flux linkage models, it can make a performance evaluation between the rotor flux voltage model and rotor flux current model [7]. Based on the evaluation, it helps to select the appropriate model to realize speed control at high precision for induction motor. The reliability of the rotor flux voltage and current models is studied in following sections.

\section{A. Research on the Rotor Flux Current Model}

The change of the frequency of the motor input voltage has directly influence on the magnetic saturation, which in turn affects the inductance of the windings. The following assumption is made: The change of the inductance causes the flux linkage to become unstable.

In order to research whether the change of the inductance in the process of starting-up and working operation exerts an influence on the flux linkage, the rotor flux voltage and current models are transformed. The new models are shown in Fig.6.

Assuming that the motor is under different speeds, the inductance value changes. This paper selects the extreme situation for simulation experiments, that is, the inductance value is set to be step signal at a point, for example, $L_{\mathrm{m}}$ and $L_{r}$ are both increased to 1.5 times than original value at a time. By resetting the parameters, the speed waveform of the modified motor model is obtained in Fig.7.

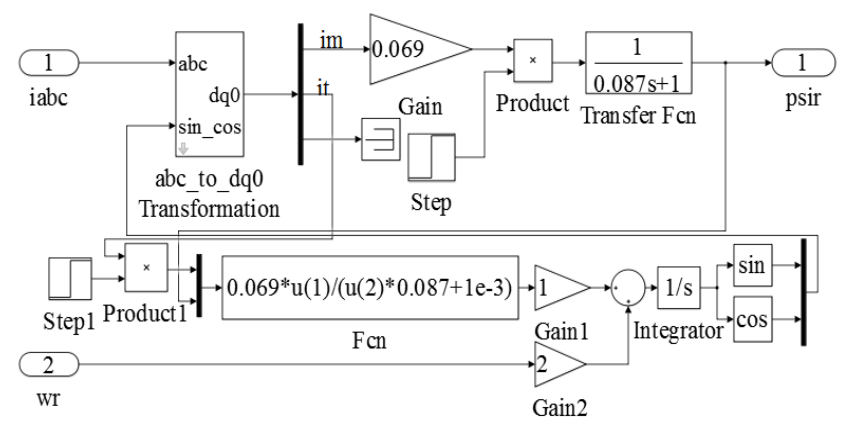

(a)

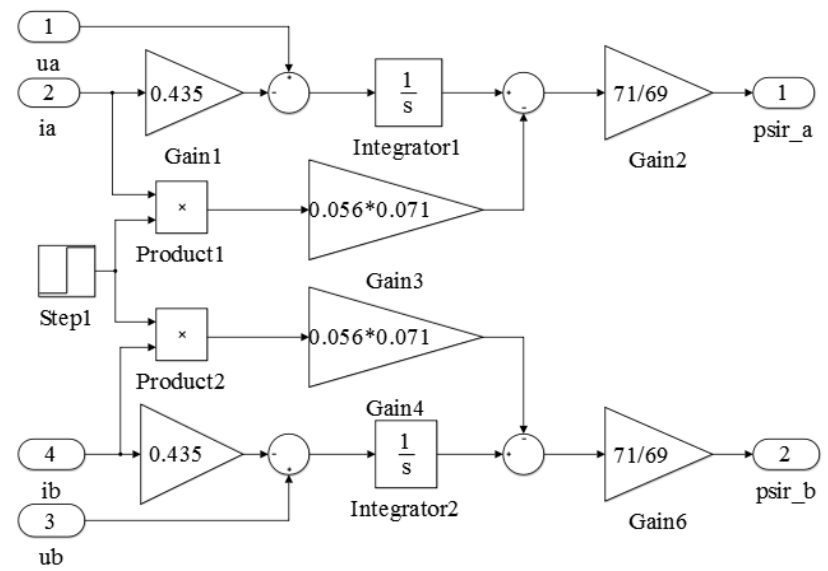

(b)

Fig. 6. (a) The transformed rotor flux current model. (b) The transformed rotor flux voltage model.

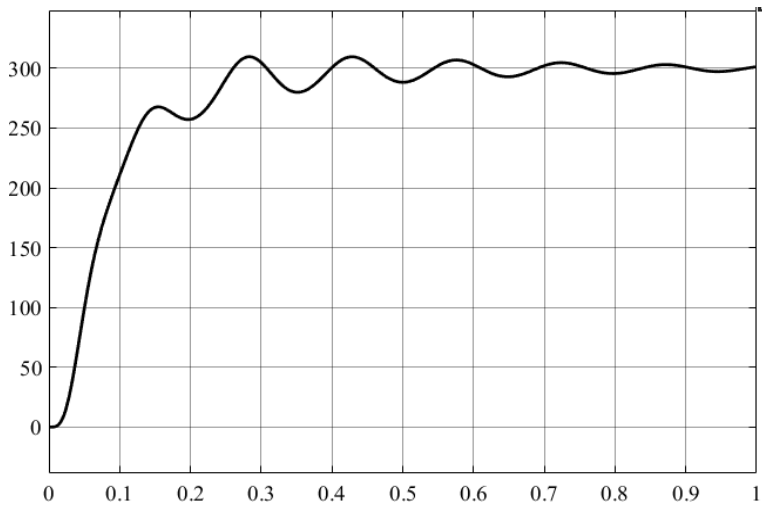

Fig. 7. The speed of motor

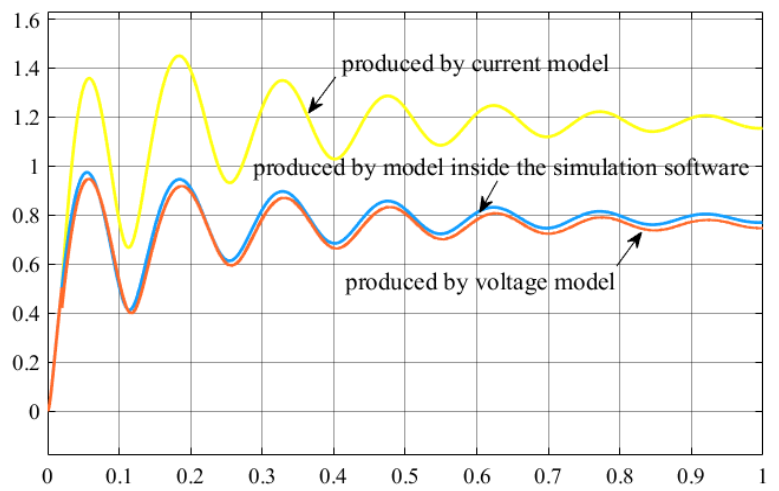

(a)

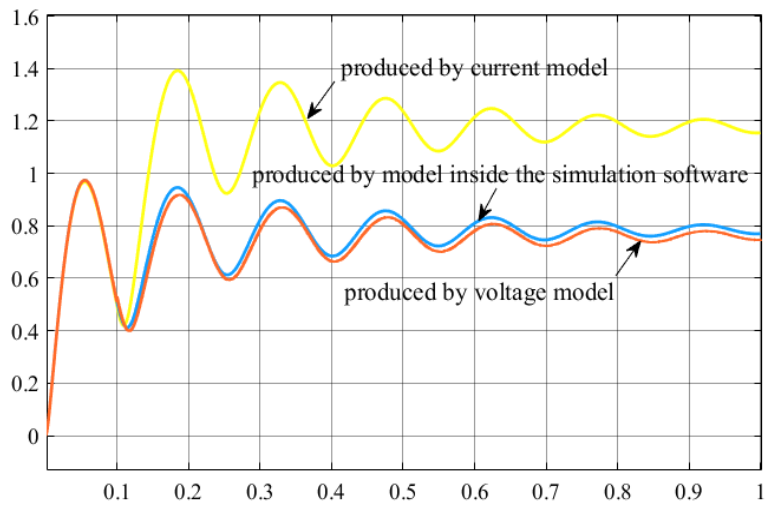

(b)

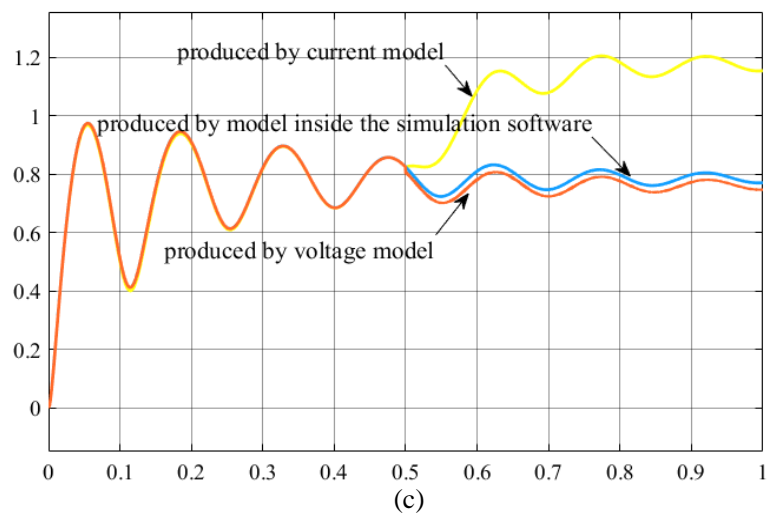

Fig. 8. (a) The step is working at $t=0.02$. (b) The step is working at $t=0.1$. (c) The step is working at $\mathrm{t}=0.5$ 
Take 0 0.02 second for the low-speed operating state of the motor, 0.02 0.1 second for the medium-speed operating state and $0.1 \sim 0.5$ second for high-speed operating state. Run the simulation and obtain the flux linkage waveform shown in Fig.8.

The modulation of the PWM modulator is 0.2 and the output frequency is $10 \mathrm{~Hz}$ in the below simulation. From the waveform, it can be seen that if the inductance value changes, the waveform of rotor current model also changes accordingly.

In summary, when the motor is at any speed, it has a great impact on the waveform of flux linkage produced by current model as soon as the change of the inductance of the winding is appeared. Therefore, the above assumption is correct-the motor parameters affect the stability of the rotor flux current model.

It can obtain the same results for the current model by running the simulation if the modulation is 0.9 and the output frequency is $50 \mathrm{~Hz}$.

Taking into account the actual situation, the motor input voltage frequency can not be static. Therefore, the waveform of flux linkage produced by current model should be fluctuated irregularly in the vicinity of that of flux linkage produced by the flux linkage model inside the software, but the overall trend of the waveform is stable. For the characteristic of stability and followability, the voltage model is better than the current model.

\section{B. Research on the Rotor Flux Voltage Model}

Take the waveform between 0.5 seconds and 0.6 second to enlarge in Figure 8(c) and the picture is shown as Fig.9.

At this time, the waveform of flux linkage produced by voltage model has a high similarity with that produced by model inside the simulation software, which can be considered to coincide with each other. And it can be seen that the voltage model is insensitive to changes of inductance values.

Based on the above conclusion, the voltage model of the motor under working operation is studied. From the rotor flux linkage voltage model, as shown in (5), it is found that there is an integrator inside the model. According to the characteristic of the integrator, the following assumption is made: The reliability of the rotor flux voltage model would be affected when the motor input voltage is not stable.

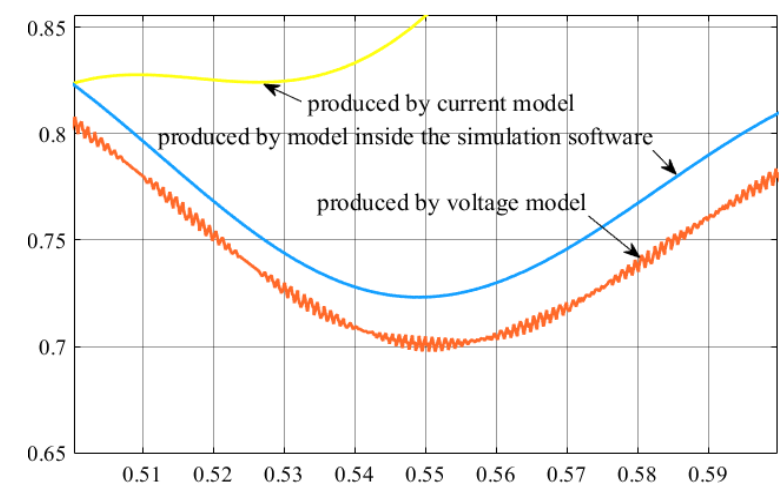

Fig. 9. The enlarged waveform with step working at $\mathrm{t}=0.5$

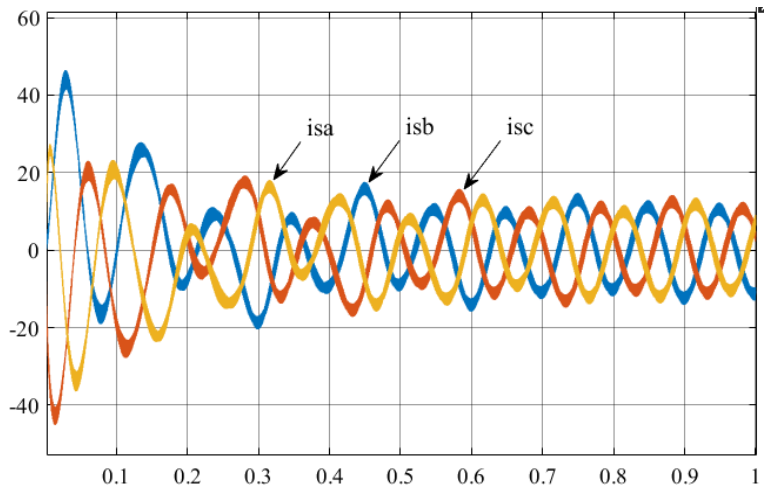

Fig. 10. The waveform of three-phase current

There is a large starting-up current for motor in the process of starting, as shown in Fig.10.

In a period of time, the stator resistance would withstand a large pressure drop, resulting in a large calculating error. This proves that the integrator in the voltage model results in a large calculating error.

In Fig.5(a), for example, enlarge the waveforms between 0 and 0.02 second and 0.5 and 0.6 second. The figures are shown in Fig. 11.

As can be seen from Fig.11, the reliability of the voltage model is not as good as that of the current model when the motor starts at low speed. This proves that the above assumption is correct.

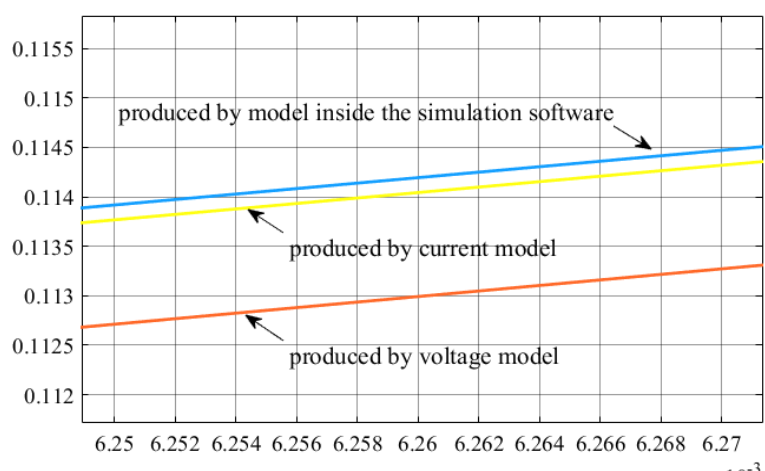

(a)

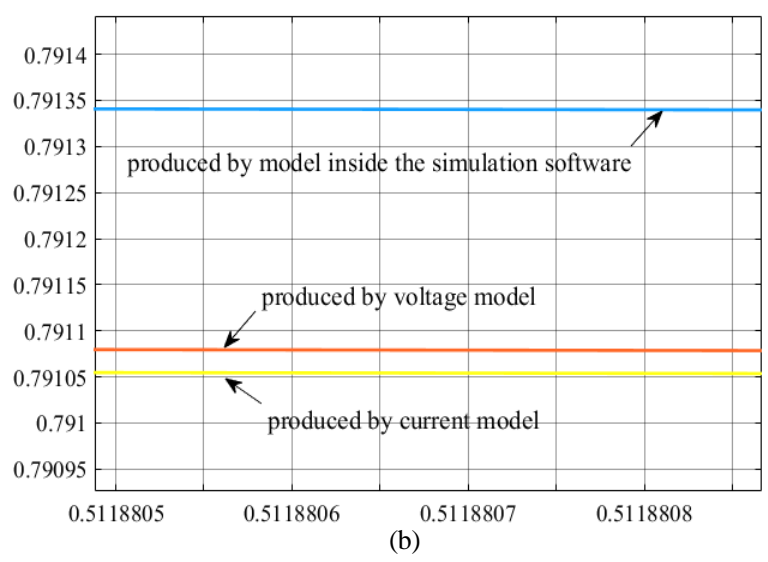

Fig. 11. (a) The enlarged waveform during $\mathrm{t}=0 \sim 0.02$. (b) The enlarged waveform during $\mathrm{t}=0.5 \sim 0.6$. 
In the reality, the error of flux linkage produced by voltage model is greater than that produced by current model caused by the fluctuations of input voltage frequency. Therefore, in the actual engineering application, the current model is relatively better for reliability if the motor is not in normal operation.

Considering the skin effect that exists during the operation of the motor, it is necessary to study whether the change of the stator resistance caused by the temperature rise affects the flux linkage model. By checking the papers, it can be found that the variation range of the stator resistance is under $0.2 \Omega$ when the motor is working [8].

In the process of simulation, the waveform of flux linkage produced by voltage model has a slight difference with that produced by flux linkage model inside the simulation software. It is because the flux linkage model inside the simulation software can not change the stator resistance at any time. This difference has little effect on the simulation, so it can be ignored. After the value of stator resistance of voltage model is increased at a certain time, it finds that: The change of value does not work on for waveform of flux linkage produced by voltage model.

\section{CONCLUSION}

For the rotor flux current model, the rotor flux linkage value calculated by the rotor current model is absolutely affected by the variation of the stator and rotor inductance values after the motor is started, which is independent of the input voltage frequency and PWM degree of the motor, and the effect exists with the change of the inductance value. As a whole, the rotor flux linkage is in a dynamic-steady state. For the rotor flux voltage model, the rotor flux linkage calculated by the voltage model is affected by the integrator existed in the model. There is a large start-up current in the process of starting for the motor, so it can generate a great integral error. In conclusion, it is not suitable for observation with the flux linkage of voltage model at this time. In this paper, the best method of observing the flux linkage of induction motor at different time is obtained by simulation analysis: For the advantages and disadvantages of the rotor flux voltage and current models, it can be seen that when the motor is in the low-speed state, it is suitable to use the rotor flux current model to observe the flux linkage, and in the medium and high speed, it is appropriate to choose voltage model for observation; Ideally, the flux linkage of the motor will eventually reach a steady state. It is proved that the speed control of induction motor can be realized by adopted the Vector Control.

\section{REFERENCES}

[1] Junyan Wang, Method of Rotor Coordinate System Observation for Rotor Flux of Induction Motor, S\&M Electric Machines, Vol.27, 2000.

[2] W. Leonhard, Control of Electrical Drives, Berlin Heidelberg New York, 2001.

[3] S.S. Park; G.H. Cho, Rotor flux controlled induction motor drive for high performance applications, Vol. 26. pp439-440, 1990.

[4] P. Liusev, G. Stumberger; D. Dolinar, Electric Power Applications, Vol. 152. pp112-118, 2005.

[5] Boshi Chen, The Electricity Pull Automation Control System-The motion Control System, Beijing, 2003.

[6] Naigang Hong, Modeling and simulation of Power electronics and Motor Control System, Beijing, 2010.

[7] Haibo Zhao, The Vector Analysis of the Traction Motor's Rotor Flux in EMU, 1. pp87-93, 2014.

[8] Boshi Chen, Induction Motor Vector Control System Oriented by Rotor Flux, Power Electronics Technology, Vol. 1. pp42-45, 2008. 